\title{
ATIVIDADES DE ENSINO E EXTENSÃO DESENVOLVIDAS PELO GRUPO PET-ELÉTRICA UFPB COMO FORMA DE APROXIMAR E ACOLHER OS ESTUDANTES INGRESSANTES AO AMBIENTE UNIVERSITÁRIO
}

\author{
DOI: 10.37702/2175-957X.COBENGE.2021.3727
}

Ítalo César Araújo Ferreira - italo.ferreira@cear.ufpb.br

Universidade Federal da Paraíba

Rua Carlos Gomes 13

58200-000 - Guarabira - PB

Miguel Marques Ferreira - miguel.ferreira@cear.ufpb.br

Universidade Federal da Paraíba

Rua Bacharel Wilson Flávio Moreira Coutinho 161

58052-510 - João Pessoa - PB

Rafael Senna Benatti - rafa.senna.benatti2@gmail.com

Universidade Federal da Paraíba

Rua Pastor Guaracy Nóbrega 95

58051-835 - João Pessoa - PB

Mariana Marques Ferreira - marianam.ferreira@cear.ufpb.br

Universidade Federal da Paraíba

Rua Clarice Pires de Sá 96

58805-020 - Sousa - PB

Nady Rocha - nadyrocha@cear.ufpb.br

Universidade Federal da Paraíba

Professora Maria Lianza 1261

58052-320 - João Pessoa - PB

Resumo: Diante do crescente número de matriculados nos cursos de graduação das instituições públicas e privadas de ensino superior brasileiras, a desigualdade existente entre o número de alunos ingressantes e formandos revela a problemática da evasão dos alunos de graduação. Problemas como a falta de associação entre conhecimentos teóricos e práticos e o desprovimento de 
perspectiva profissional são problemas que contribuem para o aumento dos índices de desistências nos cursos de nível superior. Para mais, atrelado aos problemas citados, o cenário pandêmico durante os anos de 2020 e 2021 contribuiu indiscutivelmente para o afastamento entre o corpo discente e o ambiente universitário. Visto isso, este trabalho busca-se analisar a estratégia utilizada pelo grupo PET-Elétrica da Universidade Federal da Paraíba (UFPB) para a realização de quatro atividades de ensino e extensão como forma de melhor acolher e auxiliar a permanência dos alunos ingressantes nos cursos de Engenharia Elétrica e Engenharia de Energias Renováveis da UFPB, após avaliação dos dados obtidos por meio de questionários de satisfação online e com as métricas disponibilizadas pelas plataformas digitais utilizadas.

Palavras-chave: Evasão Escolar. Plataformas Digitais de Ensino. Programa de Educação Tutorial - PET. Pandemia. 


\section{(c) $C O B E N C E$ \\ 28 a 30 de SETEMBRO \\ ATIVIDADES DE ENSINO E EXTENSÃO DESENVOLVIDAS PELO GRUPO PET-ELÉTRICA UFPB COMO FORMA DE APROXIMAR E ACOLHER OS ESTUDANTES INGRESSANTES AO AMBIENTE UNIVERSITÁRIO}

\section{INTRODUÇÃO}

No decorrer dos anos, é visível o crescimento no número de Instituições de Ensino Superior (IES) públicas assim como privadas. De acordo com o Censo da Educação Superior de 2010, o Brasil contava com 2099 IES privadas e cerca de 278 instituições públicas de ensino superior nas categorias municipais, estaduais e federais (INEP, 2011). Já no ano de 2019, o número de instituições privadas aumentou para 2306 enquanto as públicas aumentaram para 302 instituições, ambas de ensino superior, quantitativos que revelam a maior oferta de vagas para que os estudantes brasileiros possam ingressar em um curso de nível superior (INEP, 2020).

Ainda conforme o Instituto Nacional de Estudos e Pesquisas Educacionais Anísio Teixeira (INEP), no ano de 2019 o número de matrículas nas instituições de educação superior chegou a marca de 8,6 milhões nos cursos de graduação. Contudo, os números do censo também revelam que apenas 1,2 milhões de alunos concluíram os seus cursos no ano de 2019. Com estes dados, observa-se uma desigualdade entre o fluxo de alunos ingressantes e formados pelas IES, a qual está diretamente interligada com a problemática da evasão escolar no ensino superior brasileiro.

A evasão nos cursos de ensino superior representa um grande desafio para a formação de profissionais nas mais diversas áreas. Essa interrupção da formação acadêmica ocorre por diversas razões, tendo como principais causas os problemas individuais, ambiente universitário e fatores externos como, por exemplo, dificuldade financeira. (OLIVEIRA; GUIMARÃES; SANTANA, 2019).

Em especial, os bacharelados em engenharia apresentam altos índices de desistência devido, principalmente, aos seguintes fatores (SACCARO; FRANÇA; JACINTO, 2019) e (CHRISTO; RESENDE; KUHN, 2018): o nível de dificuldade dos cursos, elevada carga horária, déficit de conhecimentos em ciências básicas e consequente dificuldade nas disciplinas iniciais, a falta de associação entre conhecimentos teóricos e práticos e o desprovimento de perspectiva profissional.

No contexto atual, um outro fator que vem contribuindo para o aumento do número de trancamento de matrículas, desistência de cursos ou troca de IES é a pandemia provocada pela COVID-19, visto que as medidas de isolamento social e a interrupção das aulas presenciais obrigou os docentes e discentes a utilizarem ferramentas digitais, situação essa que expôs a insuficiência do sistema educacional do País como a falta de estrutura e habilidade com as Tecnologias da Informação e da Comunicação (TICs) (SILVA; PETRY; UGGIONI, 2020).

Além disso, novos fatores surgiram e devem ser considerados ao abordar a evasão no ensino superior, como: falta de local adequado para estudo, lacunas no acesso a recursos tecnológicos, maior sobrecarga em atividades domésticas e desgaste emocional causado pela situação vigente (NUNES, 2021).

Com essa situação, é notável a desmotivação, cansaço, estresse e ansiedade entre os alunos e professores universitários (MAIA; DIAS, 2020), trazendo à tona a necessidade de atividade extracurriculares como forma de acolher, integrar e manter os discentes estimulados com sua graduação no decorrer do curso. Em vista disso, os estudantes 
apresentam menos chances de evadir quando se encontram envolvidos no ambiente acadêmico, seja no desempenho acadêmico ou nas interações com colegas e professores (OLIVEIRA; GUIMARÃES; SANTANA, 2019).

Assim, o presente trabalho tem como objetivo apresentar a importância das atividades extracurriculares como: Lives na Engenharia, Minicurso Online em Arduino, Recepção dos Calouros e o Arduino Day 2021, desenvolvidas pelo Programa de Educação Tutorial do curso de graduação em Engenharia Elétrica (PET-Elétrica) da Universidade Federal da Paraíba (UFPB) durante a pandemia, como forma de melhor acolher e auxiliar a permanência dos alunos ingressantes nos cursos de Engenharia Elétrica e Engenharia de Energias Renováveis da instituição.

\section{ATIVIDADES EXTRACURRICULARES - DESENVOLVIMENTO}

No ano de 2020, em decorrência da disseminação da COVID-19 caracterizada como pandemia pela Organização Mundial da Saúde (OMS), várias medidas para conter a propagação do vírus foram adotadas. Desta maneira, para atender as orientações dos órgãos de saúde pública de isolamento e distanciamento social, vários setores tiveram suas atividades presenciais suspensas, em especial, o ambiente educacional, no qual foi necessário a adequação inicialmente para o ensino no formato remoto e posteriormente para o ensino híbrido.

Nesse contexto, buscando contornar os desafios impostos no sistema de ensino, as metodologias educacionais das instituições de ensino presencial tiveram que ser reformuladas com o suporte das Tecnologias da Informação e da Comunicação, passando a ser realizadas de maneira remota com o auxílio das TICs.

Um outro problema observado, devido a falta das aulas presenciais, foi um momento de interação dos novatos com o ambiente universitário, uma vez que o semestre foi iniciado de maneira remota. No caso, particular da UFPB, ocorreram dois períodos remotos, sendo um período especial de somente 2 meses, com ingresso de alunos classificados no Sistema de Seleção Unificada (SiSU) através do Exame Nacional do Ensino Médio (ENEM). Diante disso, novas ações e práticas educacionais, com o intuito de promover o aprendizado e o acolhimento, principalmente dos novos alunos, utilizando ferramentas tais como: Instagram $\AA$, YouTube $\AA$, Google Meet $\AA$, Google Classroom ${ }^{\circledR}$ e Edpuzzle ${ }^{\circledR}$ se tornaram essenciais para realizações de eventos e ações acessível a todos os estudantes.

A primeira tecnologia, o Instagram $\AA$, permite a realização de eventos ao vivo, conhecidos como lives. Por ser online, gratuita e acessível em qualquer dispositivo, um dos principais fatores que influenciaram na seleção dessa mídia social foi sua alta popularidade, tornando-a favorável para a disseminação de experiência sobre o curso de Engenharia Elétrica e a popularização das atividades do grupo PET-Elétrica.

A segunda ferramenta, o YouTube $\AA$, é uma plataforma de compartilhamento de conteúdo audiovisual que tem como missão, segundo a própria companhia, "dar a todos uma voz e revelar o mundo". Essa plataforma foi selecionada uma vez que, de forma semelhante ao Instagram $\AA$, também permite ser utilizada para o desenvolvimento de atividades ao vivo e admite o armazenamento delas para que, posteriormente, outras pessoas acessem o conteúdo audiovisual.

Já o serviço fornecido pelo Google $\AA$, Google Meet $\AA$, é uma plataforma que favorece a comunicação por vídeo chamadas entre colaboradores remotos. Desenvolvida inicialmente para empresas, a solução é compatível com a maioria dos dispositivos. Ela é uma ferramenta indispensável para alunos e professores que fazem uso desta solução para 
a realização de atividades como aulas, reuniões, palestras, apresentações, avaliações e cursos.

Para as atividades de ensino, foram escolhidas as plataformas Google Classroom ${ }^{\circledR}$ e Edpuzzle $\AA$, uma vez que o Centro de Energias Alternativas e Renováveis (CEAR) possui convênio institucional com o Google $₫$ bem como a sua fácil utilização, compatibilidade com diversos dispositivos tecnológicos e por apresentar acesso online e gratuito. O Google Classroom®, permite a criação de uma turma virtual por onde são disponibilizados os materiais didáticos, a organização dos mesmo por tópicos, o gerenciamento de tarefas e um mural para conversação para auxiliar na comunicação entre estudantes e professores com o intuito de facilitar a relação ensino-aprendizagem, como pode ser observado na Figura 1.

Figura 1 - Turma Virtual do Minicurso online de Arduino.

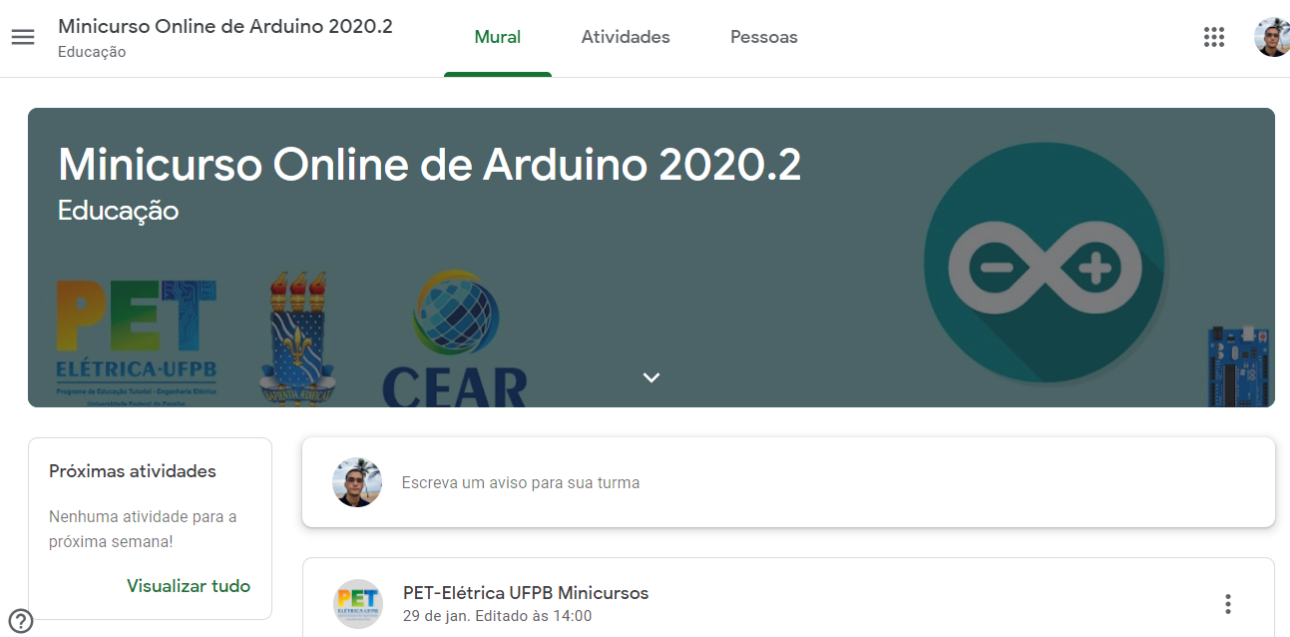

Fonte: Autoria própria.

Já a plataforma $E d p u z z l e \AA$, utilizada em paralelo com a turma virtual, é empregada para hospedagem de materiais didáticos audiovisuais na internet e para realizar o controle de participação dos alunos presentes na atividade. Por exemplo, a quantidade de participantes de uma turma, a porcentagem de visualizações e a porcentagem do tempo de aula assistida pelo utilizador são métricas disponibilizadas pela própria plataforma fazendo com que seja possível mapear os alunos de acordo com a dedicação, dificuldade etc.

Dessa forma, fazendo uso das ferramentas apresentadas anteriormente e buscando oferecer suporte acadêmico e acolhimento aos novos alunos da graduação dos cursos de graduação de Engenharia Elétrica e Engenharia de Energias Renováveis da Universidade Federal da Paraíba, surgiu a oportunidade de, em um momento sensível de pandemia, realizar as atividades de ensino e extensão descritas nas subseções 2.1 a 2.4.

\subsection{Atividade 1 - Lives na Engenharia}

\section{Introdução}

Nos cursos de engenharia, a inserção de conhecimentos práticos e a experiência com o mercado de trabalho são fundamentais durante a graduação. Atualmente, por falta de comunicação e contato com profissionais inseridos no mercado de trabalho, os alunos possuem uma dificuldade em encontrar oportunidades profissionais e planejar as suas carreiras. Essa falta de perspectiva profissional aliada a uma lacuna na associação entre 
os conhecimentos adquiridos nas disciplinas e a prática pode acarretar em desmotivação entre os estudantes.

Por esse motivo e visando diminuir a distância entre os alunos da graduação e o mercado de trabalho, o grupo PET-Elétrica promoveu o evento intitulado, Lives na Engenharia buscando facilitar a troca de experiências e orientações entre os alunos egressos, novatos e veteranos, sejam elas nas trajetórias acadêmicas ou profissionais, além das oportunidades na área.

\section{Metodologia}

A realização das Lives na Engenharia, que aconteceu durante os meses de junho a agosto de 2020, ocorreu por meio de transmissões ao vivo utilizando a mídia social Instagram $\AA$ e contou com 7 (sete) momentos com duração de aproximadamente uma hora cada. Além disso, o evento incluiu a participação de 7 (sete) convidados, com a experiência de participação em processos seletivos, ou trabalho no exterior, intercâmbios, estágios, pós-graduações, entre outros.

Em cada uma das lives, no final, era disponibilizado aos participantes um espaço para perguntas a fim de sanar dúvidas e levantar questionamentos. Para isso, durante a realização da live, foi feito o acompanhamento do chat da plataforma Instagram $\circledast$ pelo moderador para coleta e discussão das dúvidas

\section{Resultados}

Com o interesse em avaliar o alcance e a quantidade de participantes na atividade, foram recolhidas as métricas disponibilizadas pela própria plataforma do Instagram $\AA$. Assim, cada live teve cerca de 20 espectadores simultâneos. Além disso, como as gravações das atividades ainda estão disponíveis no perfil do grupo PET-Elétrica, foi observado que após 10 meses da realização da atividade, cada live apresenta em média 300 visualizações.

Dessa forma, essa atividade proporcionou aos alunos de graduação, especialmente, dos cursos de Engenharia Elétrica e Engenharia de Energias Renováveis uma nova perspectiva acerca da área acadêmica e do mercado de trabalho.

\subsection{Atividade 2 - Minicurso Online de Arduino}

\section{Introdução}

A integração entre conteúdos práticos e teóricos, principalmente nos cursos de engenharia, é de fundamental importância visto que os futuros profissionais atuarão como agentes de transformação da sociedade e como responsáveis no solucionamento dos problemas cotidianos (BATISTA et al., 2017). As atividades extracurriculares, então, são indispensáveis para o desenvolvimento de habilidades e competências necessárias para a formação acadêmica dos estudantes.

Nesse contexto, com intenção de contribuir na formação dos estudantes da graduação e ainda contornar a situação atípica de pandemia, o Minicurso Online de Arduino, realizado durante os meses de janeiro a março de 2021 com carga horária de 4 (quatro) horas, foi elaborado com o objetivo de apresentar a plataforma Arduino além de 
despertar o interesse dos alunos acerca de programação e tecnologia, viabilizando o desenvolvimento de conhecimento na área.

\section{Metodologia}

O Arduino® é uma plataforma de prototipagem eletrônica open-source muito utilizada para realizar projetos que vão desde a concepção de códigos para resolução de cálculos matemáticos simples, até projetos de automação residencial. A escolha por essa plataforma se deu devido a sua fácil utilização para usuários iniciantes e avançados, uma vez que a placa Arduino pode ser adquirida facilmente e por um preço razoável no mercado de eletrônicos brasileiro. Além disso, o software Arduino IDE é compatível com os sistemas operacionais Windows $\AA$, Macintosh OSX® e Linux®, os mais utilizados na atualidade, e pode ser obtido de forma gratuita no site (ARDUINO, 2021).

Contudo, diante da realidade de que a maioria dos estudantes participantes das atividades não tinham uma placa Arduino em mãos, a capacitação foi produzida fazendo uso do simulador Tinkercad® , da AutoDesk $\AA$, uma ferramenta online e gratuita utilizada para construção e simulação de circuitos elétricos, com o propósito de facilitar o aprendizado de todos os participantes.

Todas as aulas ministradas, bem como todo o material de estudo foram disponibilizadas na plataforma Google Classroom® e Edpuzzle $\AA$. Com o intuito de avaliar a aprendizagem dos participantes, das 10 (dez) aulas gravadas, 9 (nove) possuíam exercícios de fixação. Para mais, foi requerido dos participantes o envio de, no mínimo, 6 (seis) listas de exercícios resolvidas como também ter assistido a todas as aulas para adquirir o certificado de participação.

\section{Resultados}

A atividade de ensino, Minicurso Online de Arduino, contou com um total de 51 participantes. Desse total, $74,5 \%$ dos participantes estudavam na UFPB. Com relação ao alcance do curso, uma das vantagens do uso das TICs é a inexistência do limite físico, então alunos de outros estados das regiões Nordeste e Sudeste fizeram-se presentes na atividade, com destaque ao estado de Pernambuco (PE), no qual 5 (cinco) alunos participaram do curso ofertado na modalidade EAD, como pode ser observado na Figura 2.

Figura 2 - Distribuição geográfica dos participantes do minicurso online de Arduino.

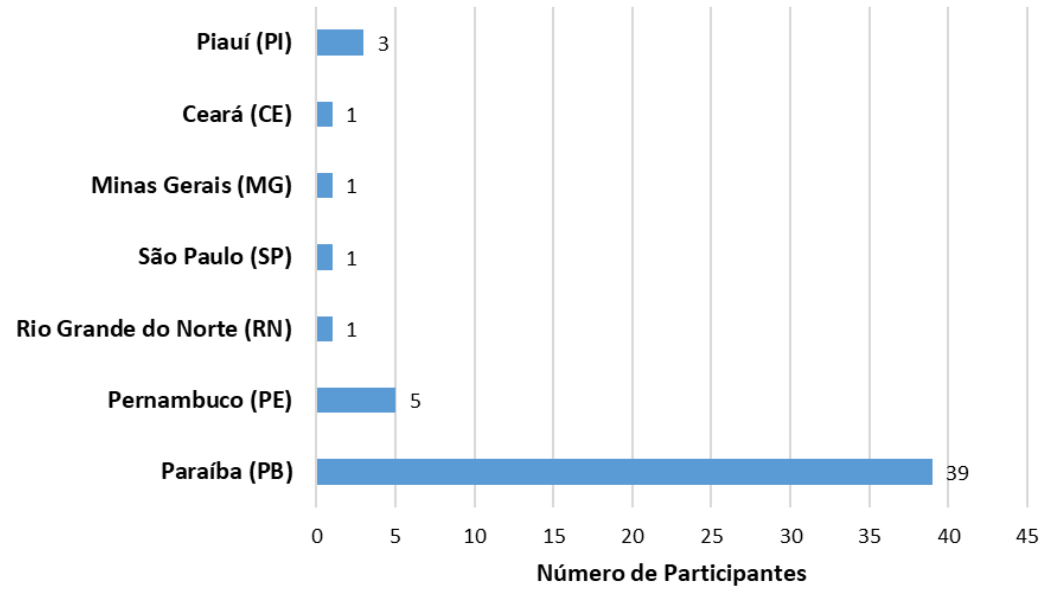

Fonte: Autoria própria. 
Para verificar o grau de satisfação dos alunos, foi compartilhado um formulário entre os participantes, quando questionado acerca da relevância do minicurso, um percentual de $87,5 \%$ afirmou que o conteúdo foi relevante e que a atividade irá contribuir para seu desenvolvimento acadêmico e profissional. Portanto, a ação de ensino e extensão chamada de Minicurso Online de Arduino promoveu o empoderamento do público alvo com assuntos relacionados à tecnologia e sobretudo, agregou experiência aos estudantes do grupo PETElétrica para o desenvolvimento de novas atividades.

\subsection{Atividade 3 - Recepção dos Calouros}

\section{Introdução}

Como forma de evitar os trotes convencionais, que muitas vezes sujeitam os calouros à situações perigosas e vexatórias durante as primeiras semanas dos períodos letivos da UFPB, o grupo PET-Elétrica, com o apoio do Centro Acadêmico de Engenharia Elétrica e do Centro Acadêmico de Engenharia de Energias Renováveis, realizam a tradicional recepção dos calouros.

A Recepção dos calouros surgiu no ano de 2014 e desde então, é realizada semestralmente com o propósito de promover a inclusão dos novos alunos ao ambiente universitário. $\mathrm{O}$ evento tem o objetivo de apresentar a matriz curricular e o diferencial dos dois cursos de graduação, assim como motivar os ingressantes através de palestras, minicursos, visitas técnicas e atividades filantrópicas.

\section{Metodologia}

Neste ano de 2021, devido às limitações impostas pela pandemia da COVID-19, a Recepção dos calouros, diferentemente das edições anteriores, foi realizada por meio das plataformas digitais Google Meet ${ }^{\circledR}$ e YouTube $\AA$, e contou com a participação dos alunos ingressantes dos semestres 2020.1 e 2020.2. O primeiro dia da recepção foi realizado com o auxílio da ferramenta Google Meetß com o intuito de promover uma comunicação direta entre todos os participantes, o que garantiu uma maior interação entre os alunos, momento esse utilizado para tirar dúvidas e trocar experiência entre os alunos veteranos e novatos.

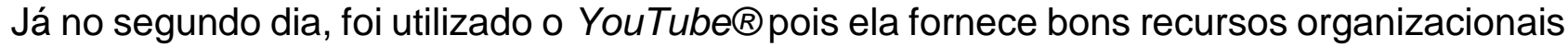
e de armazenamento para eventos como palestras e apresentações online.

O primeiro dia da recepção dos calouros, que ocorreu no dia 25 de fevereiro de 2021 , teve a finalidade de apresentar aos alunos seus respectivos centros acadêmicos e às oportunidades oferecidas pela universidade, com uma breve exposição das organizações estudantis, a citar o grupo PET-Elétrica, o Ramo Estudantil IEEE, a Empresa Júnior SIE, e os projetos de extensão, como o TREE, o grupo Fórmula Combustão, o grupo Fórmula-E e o grupo Baja da UFPB. Assim, foram concedidos 10 (dez) minutos para cada uma das organizações estudantis e, ao fim de cada apresentação, mais 10 (dez) minutos foram disponibilizados para que a equipe representante pudesse responder as dúvidas dos participantes.

Uma outra atividade realizada no primeiro dia de recepção foi a realização de uma reunião online de acolhida com os pais dos alunos ingressantes do período 2020.2. $\mathrm{Na}$ Figura 3 é apresentado o momento em que o Diretor do CEAR mostra as instalações e estruturas das salas de aula e laboratório do CEAR/UFPB para os responsáveis dos alunos. Esta atividade teve como objetivo aproximar os pais dos alunos com o ambiente 
universitário, como também evidenciar a importância do ambiente familiar no percurso acadêmico que será trilhado pelos estudantes durante a graduação.

Figura 3 - Apresentação do Diretor do Centro de Energias Alternativas e Renováveis.

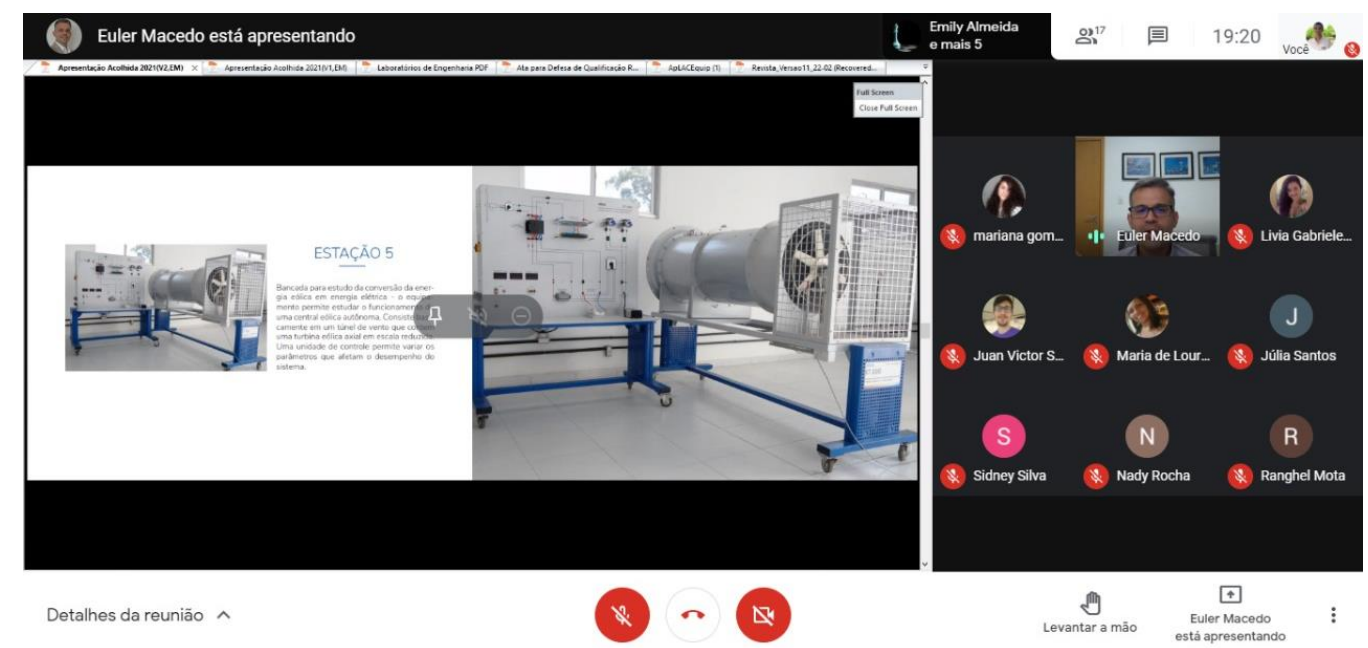

Fonte: Autoria própria.

Já no segundo dia de evento, que ocorreu no dia 26 de fevereiro de 2021, foi realizada uma apresentação online pelos coordenadores dos cursos de Engenharia Elétrica e Engenharia de Engenharia Elétrica juntamente com os técnicos administrativos. Este encontro, que foi divulgado no canal do YouTubeß CEAR UFPB, apresentou as informações básicas de cada curso como também contou com a presença do Diretor e ViceDiretor do CEAR e os coordenadores do Departamento de Engenharia Elétrica e de Engenharia de Energias Renováveis a fim de parabenizar os ingressantes.

Após essa mensagem de boas-vindas, houveram duas palestras tendo como convidado um ex-aluno do curso de Engenharia Elétrica que obteve sucesso no ramo dos negócios na área de energia sustentável bem como um ex-aluno do curso de Engenharia de Energias Renováveis que compartilhou dicas e suas experiências adquiridas no mercado de trabalho e como mestrando na Arábia Saudita.

\section{Resultados}

A atividade de acolhimento dos novos alunos dos cursos de graduação em Engenharia Elétrica e Engenharia Energias Renováveis dos semestres 2020.1 e 2020.2 somou um total de 73 (setenta e três) participantes durante o primeiro dia do evento e no segundo dia, teve 34 (trinta e quatro) participantes simultâneos. Além do mais, como o material das Lives na Engenharia, o segundo dia do evento teve sua gravação divulgada no canal do YouTube ${ }^{\circledR}$ do CEAR UFPB. Por isso, aproximadamente 50 dias após o evento, o vídeo apresenta 240 visualizações.

Um diferencial desta edição da recepção dos calouros, foi a realização de uma reunião de acolhida destinada aos responsáveis dos alunos. A nova atividade teve um quantitativo de 11 (onze) participantes, um público relativamente pequeno comparado com a quantidade de ingressantes. No entanto, os presentes relataram que a iniciativa foi de notável importância para tomar ciência da estrutura física da universidade e do corpo docente encarregados pela formação dos seus filhos.

Após o evento, foi realizada uma pesquisa de satisfação para conhecer a relevância da recepção ofertada pelo grupo PET-Elétrica para os alunos ingressantes. Com isso, na 
Figura 4 é apresentado os resultados das consultas avaliando a satisfação com a apresentação dos grupos estudantis, a apresentação das coordenações e as palestras ofertadas. Assim, pode-se verificar que a grande maioria dos estudantes classificou as atividades da recepção dos calouros como "Muito bom".

Figura 4 - Grau de satisfação dos estudantes com as atividades da recepção.

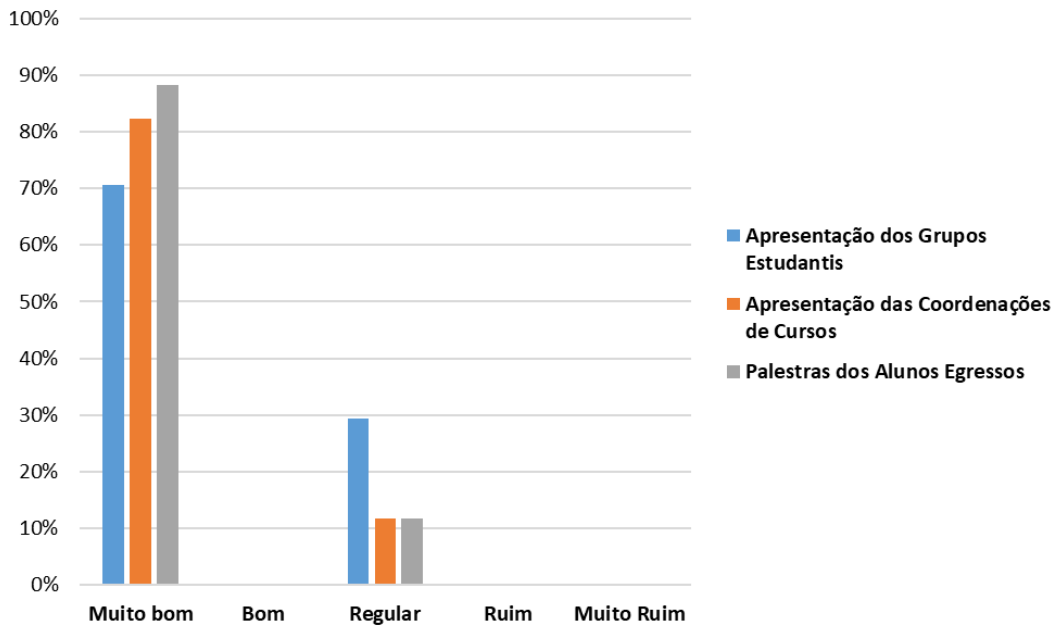

Fonte: Autoria própria.

Portanto, na edição do ano de 2021, a Recepção dos calouros apresentou de forma online a comunidade acadêmica para os alunos ingressantes, juntamente com as oportunidades internas e externas existentes na universidade a fim de incentivar a sua formação.

\subsection{Atividade 4 - Arduino Day 2021}

\section{Introdução}

O Arduino Day é uma celebração mundial do aniversário do Arduino organizada diretamente pela comunidade ou pela equipe do Arduino. O Arduino Day de 2021 foi realizado em parceria com o Capítulo Estudantil de Robótica e Automação (RAS) e foi realizado no dia 27 de março de 2021 em diversos países.

\section{Metodologia}

De maneira online, o evento contou com a seguinte programação: Palestra "Jornada dos alunos de escola pública até a Robocup", transmitida pelo YouTube® no canal RAS UFPB, quatro minicursos realizados de forma simultânea por meio da plataforma do Google Meet ${ }^{\circledR}$, sendo eles "Arduino aplicado à instrumentação eletrônica", "Desenvolvendo software para potencializar projetos com Arduino", "Integração de Arduino com Unity", "Desenvolvimento de projetos com programação básica para Arduino".

Além disso, foi realizada uma mesa redonda cuja temática foi "Aplicações do Arduino no cotidiano", transmitida pelo YouTube ${ }^{\circledR}$ no canal PET-Elétrica UFPB Minicursos. A mesa 
redonda contou com participantes com experiência na área de sistemas embarcados, com vivências em projetos que utilizam a plataforma Arduino.

\section{Resultados}

A comemoração do Arduino Day 2021 contou com o total de 331 inscritos distribuídos entre as regiões Norte, Nordeste e Sudeste, totalizando, assim, 9 (nove) estados brasileiros, em que o estado da Paraíba (PB) conseguiu o maior número de participantes, como pode ser observado na Figura 5.

Figura 5 - Estados alcançados com o Arduino Day 2021.

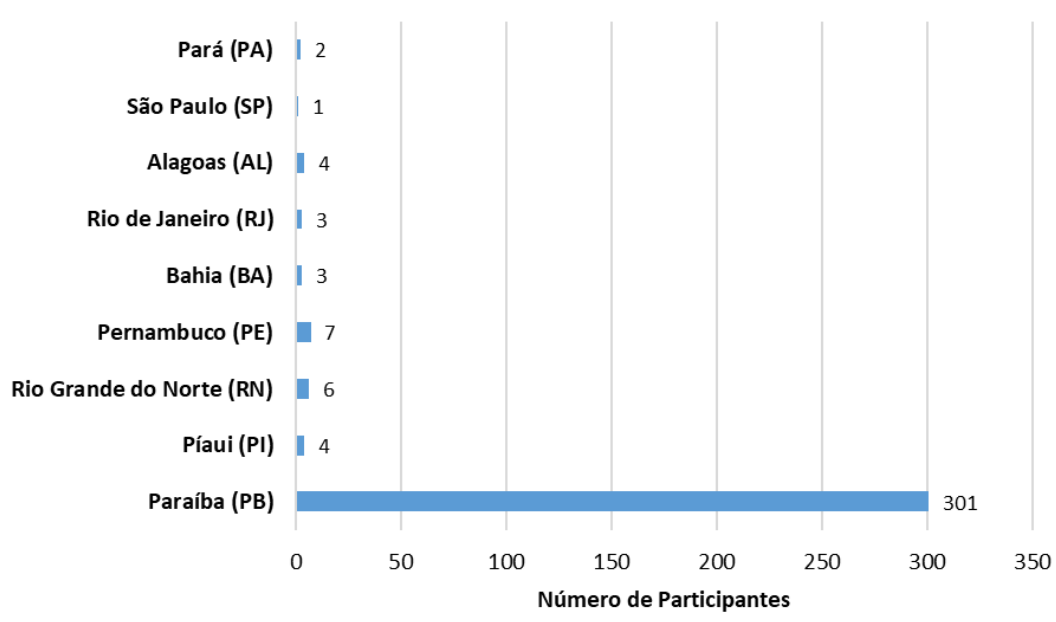

Fonte: Autoria própria.

Deste total de inscritos, cerca de 318 manifestaram interesse em um dos quatro minicursos, a relação de minicurso com a quantidade de inscritos pode ser observado na Figura 6.

Figura 6 - Relação de inscritos por minicursos no Arduino Day 2021.

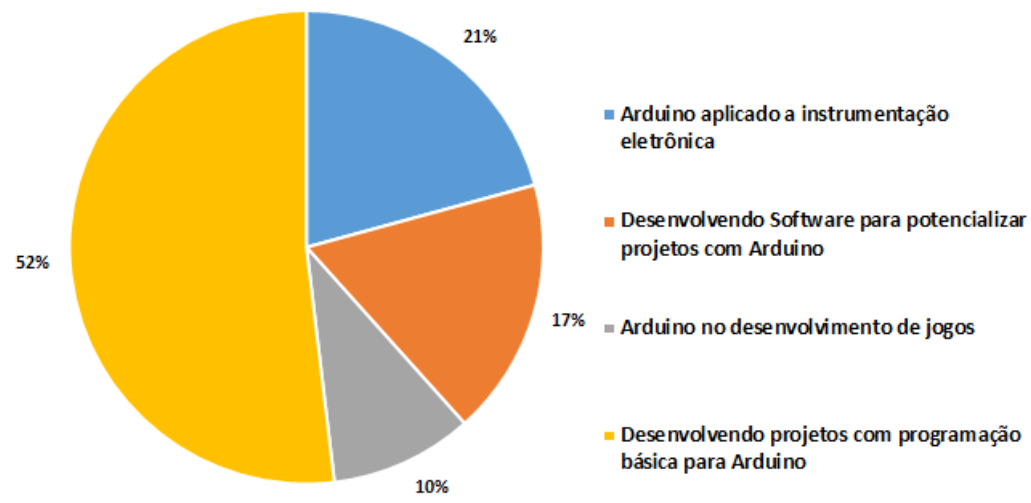

Fonte: Autoria própria.

Ainda sobre o Arduino Day 2021, aproximadamente 1 mês depois, a transmissão da palestra conta com 314 visualizações e a mesa redonda apresenta um total de 131 visualizações. 


\section{CONSIDERAÇÕES FINAIS}

Portanto, pode-se concluir que as atividades desenvolvidas pelo grupo PET-Elétrica no cenário pandêmico durante os anos de 2020 e 2021 apresentaram-se de forma relevante para o amparo e acolhimento dos estudantes ingressantes e veteranos dos cursos de graduação em Engenharia Elétrica e Engenharia de Energia Renováveis da UFPB, em especial, por serem o principal público contemplado com a recepção dos calouros e a atividade Lives na Engenharia. Estes tomaram conhecimento dos desafios e das oportunidades que os aguardam durante a graduação, uma vez que ambas atividades cumpriram com o propósito de expor e discutir as experiências vividas por estudantes egressos no ambiente acadêmico.

Além disso, as atividades como o Minicurso Online de Arduino e o Arduino Day 2021 atingiram um público mais amplo, o que possibilitou a participação de alunos de outros estados brasileiros. Assim, fazendo uso das TICs, estas ações de ensino e extensão promoveram a aproximação entre os estudantes de graduação e a tecnologia além do contato entre participantes de outras instituições brasileiras de ensino.

Em consequência da realização das atividades descritas anteriormente, a expectativa do PET-Elétrica é que o desempenho dos calouros no início do curso melhore, sintam-se mais acolhidos e a taxa de evasão seja minimizada. Já para os veteranos, é esperado que eles tenham e utilizem o conhecimento extraclasse adquirido durante as atividades de ensino para auxiliar na tomada de decisões durante e após a conclusão do curso. Quanto aos participantes que fazem parte da comunidade externa da UFPB, é aguardado que os envolvidos nas atividades oferecidas despertem o interesse nas áreas apresentadas, tenham motivação para desenvolver e aperfeiçoar o conhecimento adquirido e sobretudo, continuem a participar dos eventos desenvolvidos pelo grupo PET-Elétrica.

\section{REFERÊNCIAS}

Arduino. What is Arduino. Disponível em: <https://www.arduino.cc/en/Guide/Introduction>. Acesso em: 14 abr. 2021.

BATISTA, Willian Gomes; SANTOS, Caio Lucas dos; NASCIMENTO, Raidson Macêdo; CRUZ, Nanderson Ribeiro da; BATISTA, Paulo dos Santos. A importância da Metodologia Prática aplicada à Engenharia como fator inerente à aquisição do conhecimento profissional: o caso da disciplina de Ciência dos Materiais. VIII Jornada de Iniciação Científica, Tocantins, 27 out. 2017.

CHRISTO, Maria Marilei Soistak; RESENDE, Luis Maurício Martins de; KUHN, Talícia do Carmo Galan. Por que os alunos de engenharia desistem de seus cursos - um estudo de caso. Nuances: estudos sobre Educação, Presidente Prudente-Sp, v. 29, n. 1, p. 154168, 20 dez. 2018. Nuances Estudos Sobre Educação.

INSTITUTO NACIONAL DE ESTUDOS E PESQUISAS EDUCACIONAIS ANÍSIO TEIXEIRA (INEP). Censo da Educação Superior 2020, Brasília - DF: MEC, 2011.

INSTITUTO NACIONAL DE ESTUDOS E PESQUISAS EDUCACIONAIS ANÍSIO TEIXEIRA (INEP). Censo da Educação Superior 2019, Brasília - DF: MEC, 2020.

Ministério da Saúde. 0 que é COVID-19. Disponível em: https://coronavirus.saude.gov.br/sobre-a-doenca\#o-que-e-covid. Acesso em: 14 abr. 2021. 
MAIA, B. R., \& DIAS P. C. (2020). Ansiedade, depressão e estresse em estudantes universitários: o impacto da COVID-19. Estudos de Psicologia (Campinas), 37, e200067.

NUNES, R. C. An overview of the evasion of university students during remote studies caused by COVID-19 pandemic. Research, Society and Development, [S. I.], v. 10, n. 3, p. e1410313022, 2021. DOI: 10.33448/rsd-v10i3.13022. Disponível em: https://rsdjournal.org/index.php/rsd/article/view/13022. Acesso em: 19 abr. 2021.

OLIVERA, Bruna de; GUIMARÃES, Lucas José; SANTANA, Thainá Nunes Pires. O caminho para a redução da evasão de estudantes nas instituições de ensino superior. Revista Humanidades e Inovação, [s. I.], v. 6, 10 dez. 2019.

SACCARO, Alice; FRANÇA, Marco Túlio Aniceto; JACINTO, Paulo de Andrade. Fatores Associados à Evasão no Ensino Superior Brasileiro: um estudo de análise de sobrevivência para os cursos das áreas de ciência, matemática e computação e de engenharia, produção e construção em instituições públicas e privadas. Estudos Econômicos (São Paulo), [S.L.], v. 49, n. 2, p. 337-373, abr. 2019. FapUNIFESP (SciELO).

SILVA, Luiz Alessandro da; PETRY, Zaida Jeronimo Rabello; UGGIONI, Natalino. Desafios da educação em tempos de pandemia: como conectar professores desconectados, relato da prática do estado de Santa Catarina. DESAFIOS DA EDUCAÇÃO EM TEMPOS DE PANDEMIA, [s. I.], 2020. 


\title{
TEACHING AND EXTENSION ACTIVITIES DEVELOPED BY THE GROUP PET ELÉTRICA UFPB AS A WAY TO APPROACH AND WELCOME STUDENTS INGRESSING TO THE UNIVERSITY ENVIRONMENT
}

\begin{abstract}
In view of the growing number of students enrolled in undergraduate courses at public and private institutions of higher education in Brazil, the existing inequality between the number of incoming students and graduates reveals the problem of evasion of undergraduate students. Problems such as the lack of association between theoretical and practical knowledge and the lack of professional perspective are problems that contribute to the increase in dropout rates in higher education courses. In addition, linked to the aforementioned problems, the pandemic during the years 2020 and 2021 undoubtedly contributed to the distance between the student body and the university environment. In view of this, this work seeks to analyze the strategy used by the PET-Elétrica group at the Federal University of Paraíba (UFPB) to carry out four teaching and extension activities as a way to better welcome and assist the permanence of students entering the courses of Electrical Engineering and Renewable Energy Engineering at UFPB, after evaluating the data obtained through online satisfaction questionnaires and with the metrics provided by the digital platforms used.
\end{abstract}

Keywords: School Dropout. Digital Teaching Platforms. Tutorial Education Program - PET. Pandemic. 